\title{
A psychological ownership approach to designing object attachment
}

\author{
Weston L. Baxter ${ }^{1}$, Marco Aurisicchio, Peter R. N. Childs \\ Design Engineering, Imperial College London, London SW72AZ, United Kingdom
}

\begin{abstract}
The mental state in which an individual claims an object as theirs is called psychological ownership. Psychological ownership is associated with motives, routes, affordances, and outcomes directly linked to attachment. This research introduces psychological ownership in the context of designing object attachment and identifies affordance principles that help facilitate it. A framework presenting the motives for and routes to psychological ownership is proposed to provide a holistic understanding of object attachment. In the framework each route to psychological ownership, that is, control, intimate knowledge, and self-investment, has a corresponding class of affordances. Overall a total of 16 affordance principles are identified through contextual inquiry with 4 objects (a car, a mobile phone, a pair of shoes, and a park bench). Previous studies have identified various elements of this framework but have fallen short of clearly defining and relating the motives, routes, and affordances to psychological ownership identified here. These affordance principles are readily mapped to experience design models and provide a practical resource for designers. Together, the framework and the affordances inform design decisions and move towards a prescriptive design method for facilitating object attachment.
\end{abstract}

Keywords: design strategy, emotional attachment, affordance design, psychological ownership, object attachment

Individuals often develop intimate relationships with the objects that surround them. One type of such relationship is feeling a sense of ownership over an object. This feeling may occur with objects legally owned (my book), shared (my seat on the bus), or abstract (my idea, my organisation, my city). This observation has led to the construct of psychological ownership - the mental state in which individuals feel that the target of ownership is 'theirs' (Pierce, Kostova, and Dirks 2001).

\footnotetext{
${ }^{1}$ Corresponding author. Email: w.baxter13@imperial.ac.uk
} 
Psychological ownership is useful in describing personal attachment—perceived psychological closeness to an object (Baumeister, Wangenheim, and Florian 2014). Shu and Peck (Shu and Peck 2011) directly link psychological ownership to feelings of attachment. They show that psychological ownership determines the presence of a loss, and affective reaction determines the magnitude of the loss. Other studies relate psychological ownership to various aspects of attachment such as users giving an object a higher valuation (Franke, Schreier, and Kaiser 2010; Reb and Connolly 2007), developing a sense of stewardship (Davis, Schoorman, and Donaldson 1997; Hernandez 2012), and avoiding loss (Baer and Brown 2012; Kahneman and Knetsch 1991). Though it was explored mainly within the organisational context, psychological ownership can occur for any object that is visible, attractive, interesting, and experienced by an individual (Pierce, Kostova, and Dirks 2003).

Attachment is related to interaction design or experience design, which both aim to intentionally create user behaviours and experiences (Hassenzahl and Tractinsky 2006; Shedroff 2001). Similar to research on psychological ownership, design-oriented studies show great interest in affective response (Barnes and Lillford 2009; Desmet and Hekkert 2007; Krippendorff 2005; Norman 2005; Ortíz Nicolás, Aurisicchio, and Desmet 2013; Schifferstein 2010; Schifferstein 2009) and attachment (Franke, Schreier, and Kaiser 2010; Mugge, Schifferstein, and Schoormans 2010; Mugge, Schoormans, and Schifferstein 2009; Mugge, Schifferstein, and Schoormans 2006; Norton, Mochon, and Ariely 2011). Creating experiences, however, is difficult partly due to their complexity. This is particularly true when the experience is directed at a target object (Oatley and Johnson-Laird 1987). It follows that experiences cannot be designed, only designed for through affordances (Pucillo and Cascini 2014). Affordances are simply the possible interaction with and use of an object based on the properties of the object and capabilities of the user (Norman 2013). Recently, affordance-based design has received significant attention among design researchers (Maier 
and Fadel 2009; Maier and Fadel 2003; Pucillo and Cascini 2014; Srivastava and Shu 2013; Xenakis and Arnellos 2013; You and Chen 2007).

The premise of this paper is that the construct of psychological ownership is useful in understanding why and how individuals develop attachment to objects. Previous design studies on attachment (Jung et al. 2011; Mugge, Schoormans, and Schifferstein 2009) have covered partial aspects of the construct of psychological ownership but have fallen short of producing a comprehensive understanding. The construct of psychological ownership offers a more holistic approach to object attachment in design, and has, therefore, been chosen as the lens through which the research is conducted. The aim of this paper is twofold: (1) introduce psychological ownership as a construct for designing experiences and interactions leading to object attachment; and (2) identify affordance principles to facilitate these experiences and interactions. The aim is accomplished by mapping motives and routes to experience design frameworks (Hassenzahl 2010; Hassenzahl 2003; Pucillo and Cascini 2014) and identifying affordance principles through contextual inquiry with 16 users.

The paper is structured in four main sections. In the first we present and explain a framework for psychological ownership-based attachment. In the second we elaborate on the framework by reporting on ethnographic studies of user-object attachment and using the results to propose 16 affordance principles. In the third and fourth sections we discuss the results and draw conclusions.

\section{Object attachment as psychological ownership}

Psychological ownership is defined as "that state in which individuals feel as though the target of ownership (material or immaterial in nature) or a piece of it is theirs" (Pierce, Kostova, and Dirks 2001). It occurs through the experience of fulfilling ownership 'motives' (why an individual wants to own) through 'routes' to ownership (what an individual does to 
own) (Pierce, Kostova, and Dirks 2003). Attributes of the ownership target determine its ability to fulfil motives of ownership and therefore mediate ownership feelings (Peck and Shu 2009; Pierce, Kostova, and Dirks 2003; Shu and Peck 2011). If the object lacks necessary attributes or, as McCracken (McCracken 1986) explains, if individuals do not find meaning in the object's symbolic attributes, no feelings of ownership emerge. This can be true even for legally owned objects where the owner never seems to take possession of it.

Developing feelings of ownership occurs through experiencing a product. As such, in this section previous work on experience design and psychological ownership is used to inform the development of a framework for psychological ownership-based attachment. Design research has proposed various experience design frameworks (Hassenzahl 2010; Hassenzahl 2003; Pucillo and Cascini 2014). In Hassenzahl's model (Hassenzahl 2010), designing experiences is mediated by interactive objects and governed by goal-directed actions. There are three hierarchal goals in this model: be-goals, do-goals, and motor-goals. Be-goals (e.g. to be in control) motivate and reflect the needs or desires of the individual. These in turn lead to do-goals that are more concrete (e.g. control the car). Finally, motorgoals describe how the do-goals are achieved (e.g. moving the steering wheel). Pucillo and Cascini (Pucillo and Cascini 2014), building on Hassenzahl's goal-based model, have proposed a framework of user experience in interaction based on affordances. This model is adopted in the present study and instantiated in the context of psychological ownership. Begoals are matched to the motives for psychological ownership: efficacy and effectance, selfidentity, and having a place. Do-goals are mapped to the routes to psychological ownership: control, intimate knowledge, and self-investment. The routes are broad and leave room for more specific affordance principles to be identified within each route. Motor-goals refer to actions to complete the routes. This model is bidirectional in that motives encourage actions and actions, in turn, fulfil motives. The motives and routes for psychological ownership 
shown in Figure 1 are taken from the theory of psychological ownership by Pierce et al. (Pierce, Kostova, and Dirks 2003; Pierce, Kostova, and Dirks 2001) and are detailed in the next section. These are followed by a brief summary of affordances.

\section{[Enter Figure 1 Near Here]}

\subsection{Motives for psychological ownership}

Psychological ownership is driven by three main motives: efficacy and effectance, selfidentity, and having a place (Pierce, Kostova, and Dirks 2003; Pierce, Kostova, and Dirks 2001). These motives are analogous to be-goals as shown in Figure 1. Understanding these motives is a foundation for developing successful user attachment.

\subsubsection{Efficacy and effectance}

Snare (Snare 1972) describes ownership as a special relationship in which the owner has the right to use, sell, transform, or extend (deny) access to others. In essence, the owner has ultimate control over the object. To be in control is one of the driving motives of possession (Isaacs 1933). Being in control creates positive feelings of efficacy and it creates pleasure as desired outcomes are created. The desire to be able to control or alter an environment (efficacy) leads to feelings of competence or effectance.

\subsubsection{Self-identity}

Objects help create, continue, or transform our identities (Russell W. Belk 1988; R. W. Belk 1987; Kleine and Baker 2004; Schouten 1991; Tian and Belk 2005). The objects we own communicate meaning to others and ourselves (Richins 1994b; Richins 1994a). Individuals seek out objects to create and communicate an identity in an attempt to be (or appear to be) a desired person. 


\subsubsection{Having a place}

An important human need is to have a place (Weil 1952). Familiar objects often help people feel like they have a place or a home (Mehta and Belk 1991) and those that are most effective are likely to be the possessions receiving significant emotional investment (Porteous 1976). This familiarity, or place of their own, leads to a sense of security (Pierce, Kostova, and Dirks 2003). This encourages people to devote significant resources to take possession of target objects that can potentially become their home.

\subsection{Routes to ownership}

Do-goals illustrated in Figure 1 are analogous to the three routes to ownership: control, intimate knowledge, and self-investment (Pierce, Kostova, and Dirks 2003; Pierce, Kostova, and Dirks 2001). Prerequisite to these routes is a degree of attractiveness of the ownership target that, as mentioned previously, mediates psychological ownership. If an individual is not attracted to the target they may not engage with any of these routes. When individuals are exposed to an object it generally becomes more preferable (Fang, Singh, and Ahluwalia 2007; Zajonc 1968) though this does not always occur if the object is unpleasant (Meskin et al. 2013; Peck and Shu 2009). Feelings of ownership also may be prevented or hindered due to contamination — disgust in response to an offensive object (Angyal 1941; Argo, Dahl, and Morales 2008; Argo, Dahl, and Morales 2006; Bardhi and Eckhardt 2012; Hejmadi, Rozin, and Siegal 2004; Meigs 1984; Nemeroff and Rozin 1994; O’Reilly et al. 1984; Rozin, Markwith, and McCauley 1994; Rozin et al. 1989; Rozin, Millman, and Nemeroff 1986; Rozin and Fallon 1987). In such cases, individuals often need to strip an object of evidence of another person before taking possession of it (McCracken 1986). Thus, contamination acts as a moderating variable in which case a user may feel like the object is someone else's until it is cleansed and the individual can take possession of it. 


\subsubsection{Control}

Control is both a characteristic of ownership (Snare 1972) and a route to achieving it (Csikszentmihalyi and Halton 1981; Sartre 2012). In the context of everyday life, people frequently use small acts of control to make an object theirs (e.g., adjusting the height of a chair). The importance of control in developing ownership is partly demonstrated by the consequences of users losing control of objects. Several studies (Halme et al. 2006; Kahneman 2011; Stø et al. 2008) highlight the lack of ownership and control over an object as a barrier to adopting less traditional modes of consumption.

\subsubsection{Intimate knowledge}

Feelings of ownership rise with information and familiarity about the object. Pierce et al. (Pierce, Kostova, and Dirks 2003) argue that feelings of ownership can begin to occur almost immediately. Evidence of this is the increased valuation or sense of ownership following even basic exposure to a stimulus (Peck and Shu 2009; Zajonc 1968). Exposure to a stimulus represents some gained knowledge (i.e., what it looks or feels like) though it takes time for the emotional aspect of ownership to strengthen (Strahilevitz and Loewenstein 1998). Time allows an individual to get to know an object's basic features but also allows an individual to identify those features that differentiate the object from its nearly identical mass-produced counterparts. Jung et al. (Jung et al. 2011) identified this intimacy with an object over time as an important factor in developing love for objects.

\subsubsection{Self-investment}

Investing personal resources such as time, money, physical effort, and psychological energy into an object allows users to make the object (or part of it) theirs. In these conditions, "labor leads to love" (Norton, Mochon, and Ariely 2011) as the individual develops a special 
connection with the object and the object even becomes part of the individual's extended self (Russell W. Belk 1988). Self-investment strategies often fall under a myriad of activities related to mass-customization (Ferguson, Olewnik, and Cormier 2014; Fogliatto, da Silveira, and Borenstein 2012; Mugge, Schoormans, and Schifferstein 2009; Reeves, Tuck, and Hague 2011).

\subsection{Affordances}

An individual's ability to claim something as theirs depends on how well the target of ownership allows an individual to control, intimately know, and self-invest (Pierce, Kostova, and Dirks 2003). In other words, feelings of ownership require affordances from the target object. Affordances are possible interactions with, and use of, an object given the properties of the object and capabilities of the user (Norman 2013). A step, for example, affords stepability to an adult, but not to a young toddler (Pucillo and Cascini 2014). Originally, affordances were developed within psychology (Gibson 1977) but have since been well explored within design (Maier and Fadel 2009; Maier and Fadel 2003; Xenakis and Arnellos 2013; You and Chen 2007).

\section{Affordance principles for psychological ownership}

This study aims to identify affordance principles aiding in the development of psychological ownership. This is accomplished through a series of contextual observations that give insight on how and why people interact with objects. This approach is similar to that of Srivastava and Shu (Srivastava and Shu 2013; Srivastava and Shu 2012) who identified affordance principles for environmentally conscious behaviour. In their studies, observing lead users provided insights to design patterns that were then abstracted to general affordance principles. Key to the value in their work and the present study is balancing abstraction and specificity, that is, principles have to be abstract enough to be considered for a wide range of 
objects and at the same time be specific enough to provide meaningful design direction. Selfinvestment, for example, is certainly a design principle. It gives general directions of what the design should achieve in terms of behaviour but little direction as to how this is achieved. Polishing a pair of leather shoes is far too specific to be considered for a wide range of objects. A good principle under these conditions might be termed "maintenance," which is a sub-principle of self-investment and includes behaviours for many products including polishing shoes.

\subsection{Method}

In this study, affordance principles relevant to psychological ownership are identified through contextual inquiry. Contextual inquiry is a design research method comprising observations and interviews in the context of object use (Beyer and Holtzblatt 1999; Beyer and Holtzblatt 1997; Holtzblatt, Wendell, and Wood 2004; Martin, Hanington, and Hanington 2012). This has the potential of gaining insight beyond the consciousness of the observed user.

The studies were structured using the 'AEIOU' (activities, environments, interactions, objects, and users) contextual inquiry framework (Wasson, 2000) and semi-structured questions around the motives and routes to ownership. 'AEIOU' helps quickly identify observed elements and their interactions. This framework focuses on micro-level factors and as a result it does not guide in the identification of broader patterns. Accordingly, general questions regarding motives and routes were used to capture broader pattern-focused observations and thoughts (e.g. How does this object reflect you? What makes this object uniquely yours?). Four studies were carried out for each of the four selected object categories resulting in a total of 16 data points. Each data point represents an in-depth investigation of user-object relationships which by themselves could represent case studies. The data from these studies were transcribed and analysed through an iterative process to identify patterns 
(e.g. trends in behaviours that achieve one of the motives of ownership). Patterns were abstracted to general affordance principles that were subsequently classified according to their ability to help the user control, intimately know, or self-invest in the object.

\subsubsection{Objects}

Four objects — a car, a mobile phone, a pair of shoes, and a park bench—were chosen from which user-object relationships would be observed, assessed and analysed. The objects were chosen to show varying levels of complexity, size, value, and context. All objects are generally familiar, making insight more easily described and understood.

After housing, the car is often the largest individual household expense. Cars are unique in that they form a self-contained environment that houses the user during operation. This environment is increasingly complex with significant amounts of technology. Cars also tend to serve significant functional (e.g. transportation) and symbolic (e.g. status) value for the user. Cars were chosen to understand how a person takes ownership of large, expensive, complex, and meaningful objects.

Mobile phones are transforming technological and interpersonal interactions. They have an incredible global presence with 6.8 billion mobile phone subscriptions at the end of 2013 (ITU, 2014). Phones are one of the only objects nearly always carried by users and while essentially identical on the outside, phones are greatly personalised through their software. This study includes smart-phones to investigate an object with personal sentiment and a strong software component.

Shoes differ from the first two objects in that they carry with them very little technology. They are among the most fundamental and functional possessions. More than the other objects, multiple pairs of shoes are owned and switched out depending on the circumstance or required interactions. Including shoes in this study provides insight into 
principles behind how low-tech items with ready functional alternatives become owned. The shoes worn by users at the time of the study were investigated and compared to other shoes in their possession providing insight into multiple objects.

Finally, the park bench is a radical alternative to the other objects. Like shoes, it has few, if any, technological features. In contrast to the other three objects, the bench is stationary and is not legally owned by the user. Despite no legal ownership, the bench still induces feelings of ownership (e.g. he is in my place). More than the other objects, having a place is the likely motive behind feelings of ownership for the bench.

\subsubsection{Observations and interviews}

Each object was observed with four participants for a total of 16 observations. The study was conducted between June and August 2014. Participants for the car, phone, and shoes were selected to provide a broad demographic range (age, gender, occupation, etc.) and all studies were done in the context of using the object. Studies for the first three objects lasted an average of 93 minutes. The park bench was studied in context (London's Hyde Park) but it differed from the others in that participants were approached at the location rather than selected beforehand. These participants used the bench for a minimum of 30 minutes. All participants were informed of the study and gave consent to be questioned, observed, and referenced in any publications provided they were not identified in the publications. Table 1 provides a summary of the participants and their characteristics. Notes were taken during the observations following the 'AEIOU' and semi-structured question format previously discussed in this section and were later transcribed. Following the observations, an iterative process was used to analyse the data and identify patterns and principles.

[Enter Table 1 Near Here] 


\subsection{Results}

The 16 data points were analysed to identify affordance principles for psychological ownership. As expected, there are significant differences between the nature and strength of the interaction between motives, routes, and affordances per object type. For example, a park bench is closely associated with the 'having a place' motive but has weak ties with the 'selfidentity' and 'efficacy and effectance' motives. This contrasts with cars, phones, and shoes, which were more closely aligned to the 'self-identity' and 'efficacy and effectance' motives. This was not surprising since the latter three objects are often purchased for style, prestige or functional utility. However, it was surprising that these objects, initially intended to fulfil 'self-identity' or 'efficacy and effectance' motives, were found to fulfil the 'having a place' motive as well. For example, a car might be initially purchased for functional reasons (efficacy and effectance) and a specific car chosen for its aesthetic appeal (self-identity). However, over time, the car might also become a place to think, relax, or escape (having a place). Interestingly, all the routes were present for all the objects. Overall, this provides a useful basis from which differing interactions are assessed to identify patterns and principles of attachment.

In total, 16 affordance principles were identified and categorised according to the route (control, intimate knowledge, and self-investment) that they afford (see Table 2). All affordance categories were considered as widely as possible to reflect diverse interactions. Control affordances describe spatial and temporal control as well as the user's ability to change the object. Intimate knowledge affordances reflect ways to allow an object to communicate more accurately with the user. This communication occurs through object features as well as contextual factors. Self-investment affordances represent the range of user effort spent on interacting with an object. 
The remainder of this section defines the affordance principles using examples. The list of affordance principles is not expected to be complete. Rather it is considered to be a step toward more intentional design decisions leading to psychological ownership and attachment.

\subsubsection{Control}

Spatial Control refers to the ability to manipulate objects through space. Shoe wearers reported adjusting how (S1) the shoes were laced or how tightly (S2). Phones were regularly angled when watching a video (P1, P3), taking a "selfie" (P2), or showing photos to others (P4). The car allowed all users to pursue their own driving style. When interacting with the bench, B4 moved their bodies into a diagonal position for comfort, while B3 moved along the bench to find a higher and flatter portion of the ground. There was a perceived sense of frustration when users were not able to manipulate the object as desired such as while taking a "selfie" (P3) or trying to parallel park (C2). Users make the object theirs by adapting the object to a more desirable position.

[Enter Table 2 Here]

Configuration Control is the ability to arrange object settings. Cars have a remarkable amount of settings that can be changed by the user: lower seat position, seat back position, seat belt height, volume control, steering wheel height, rear-view mirror position, side-view mirror position, audio selection (radio, $\mathrm{CD}$, or other), window controls, vent directions, etc. Cars are particularly informative in creating one's own place, especially when shared. "Sometimes I get in the car and my husband has been driving [it]" recalled C2 and "the first thing I have to do is adjust the seat and mirror so it is comfortable again". In the phone's case, all users reflected back to when it was new and noted that it did not become theirs until they had transferred their contacts, set their password, chose a background or 
ringtone, or configured other settings. These examples show how an ability to configure an object quickly makes that object a possession.

Temporal Control is the ability to use the object when desired. The first three objects were praised because of convenience. "I love that I can get out of the city for the weekend with my car" (C4). "[My phone] lets me easily connect with friends all the time" (P2). "I grab my shoes and just go for a run" (S2). These cases all reflect temporal convenience-doing what they want when they want to. An interesting finding was that temporal control was equally important for the park bench. B3 indicated that she specifically took time to come to a particular spot (and bench). If people were already there, she felt that they had taken her bench. This principle of temporal control is distinct from delayed gratification, which typically reflects the user giving up an immediate reward for a later one. The act of giving up something is self-investment and is reflected in the creation principle (e.g. my sacrifice has created this opportunity for me).

Rate Control reflects the ability to use the consumables of the object as desired. Two cases in particular highlighted the boundaries placed on the feelings of ownership. Smart phone users P1 and P3 both commented on the pay-as-you-go data plan that they had used. In these cases, the users prepay for how much data can be transferred to and from the phone. Towards the beginning of the month, the phone is used as desired but with several days remaining in the month allotted data from the service provider occasionally runs out and usage is restricted. As P3 explained, "it is just a reminder that the phone company actually controls how you use your phone."

Transformation Control is the ability to alter the object during a given period of use. Through transformation, the object becomes something unique compared to when it was 
received. This differs from configuration control in that it does not just change the settings of the object but it alters fundamental aspects of the object. S4 recalled trying on second-hand shoes and how you could tell someone else had worn it. Or, as S2 explains, "a shoe becomes yours once you have worn it in." While none of the bench participants in this study reported marking the bench, it was obvious that others had etched words or pictures into the paint in order to leave their mark. This transformation control was a way that users leave a personal mark on the object and thereby make it theirs.

\subsubsection{Intimate Knowledge}

Ageing is the process of growing with the user. This is related to the literature on aesthetic changes in objects (van Hinte 1997; Van Nes 2010) but in this study it specifically relates to the interaction between the object and the user. These interactions often result in dents, scratches and stains that are associated with stories of use. Seldom does anyone besides the user know the origin of a scratch or dent and so this reinforces a bond between the object and the user built on intimate knowledge. S3 shared the origin of barely noticeable super glue along a shoe seam that came undone and was later fixed. P3 showed the barely noticeable mark on the corner of her phone and recounted the time in which she dropped it. Careful design could determine the extent to which object features may age over time to record and communicate user-object experiences.

Disclosure is the process of the object conveying information, meaning, and/or value. This is unique from ageing in that it describes a state of the object independent of current user interaction. Disclosure may result from the context of the object (environment, time period of use, etc.) or the object itself (origin, functions, features, value, etc.). B3 felt an attachment to a particular park bench because of the proximity to the Peter Pan statue nearby and associated memories. This extra knowledge made the bench "magical" and more than just a place to sit. 
C3 inherited a family car used by other family members while they were at college. Stories from previous users were carried in torn fabric, dents, the odometer, and other features. The miles and experiences were then for him to continue. At times, disclosure can be negative as is the case of contamination - the disgust experienced knowing that another has touched an object (Angyal 1941; Argo, Dahl, and Morales 2006). Under car sharing schemes, this seems to be one impediment to individuals developing a sense of ownership over the cars (Bardhi and Eckhardt 2012). Contamination comes from a number of sources and should be carefully mediated in design (Baxter, Aurisicchio, and Childs 2015).

Periodic Signalling is the process of object communication on an event-dependent basis. Periodic signalling provides a source of knowledge often exclusive to the user. Examples of periodic signalling include the rumble of an engine when stopped for a period of time (C3), mobile application failure during a particular sequence of use (P2), and the squeak of a shoe when wet (S3). In these cases the individual seemed to gain a more intimate knowledge of the object because of a quirk subtle enough that someone not familiar with the object may not notice and certainly would not anticipate.

Enabling is a principle reflecting the meaning carried by those objects directly mediating meaningful experiences. Participants often described objects in terms of what they afford for the user: the car that I take on road trips $(\mathrm{C} 1)$; the bench that allows me to retreat from the city (B1); the phone that lets me stay connected (P1, P2); the pair of shoes I use for running (S2). The knowledge in these examples seems to be that these objects are used to create meaningful experiences. This is useful even if the experience is not planned as is the case with a road trip (C1). In essence, the knowledge that an object provides control to do something or to fulfil a desired self-image makes it more yours. 
Simplification of external stimuli can allow greater opportunity to bond with the object. It is not likely that consumers can develop relationships with all or even many objects due to the required effort. Eliminating or minimising other interactions can help focus attention on the object at hand. This can be done through a number of design measures. The hectic nature of commuting on public transport can become much more peaceful with headphones. Two users commented that with headphones, distractions were quieted leaving much more focus on the audio coming from the phone (P1, P3). Riding in the car with $\mathrm{C} 1$ and $\mathrm{C} 4$ showed a dramatic reduction in external noise (particularly in the city) and a greater focus on internal stimuli such as music being played. S2 and S3 discussed how their workout shoes were one of only a few items used during exercise. In the case of the park bench, simple environments were sought $(\mathrm{B} 1, \mathrm{~B} 3)$ which already made the bench one of the only objects with which they could interact. Eliminating stimuli focuses on the objects at hand and allows for greater interaction, and therefore knowledge, of those objects present.

Proximity to the individual is one way to increase the likelihood that a person more intimately gets to know the object. All phone and car users, for example, were able to identify subtle features that would be missed if the object was not close to the person. Shoe features, such as a point where the fabric had worn, were reported inside the shoe $(\mathrm{S} 1, \mathrm{~S} 4)$ that could only be felt. Many objects require close proximity by their very nature (e.g. one sits on a bench, a phone goes in a pocket close to the skin, a shoe covers a foot, you completely enter a car). Designs can also encourage close contact such as earphones entering the ear. Close proximity enables people to identify subtle features that would otherwise go unnoticed.

\subsubsection{Self-investment}

Creation can be regarded as the process of bringing something into existence. Users can create an object from scratch or participate in some level of co-creation (e.g. personalise 
the object). Money, representing effort, is exchanged for goods and may also invoke feelings of creation (Sartre 2012). Involvement of users in the creation process has been explored (Franke, Schreier, and Kaiser 2010; Mugge, Schoormans, and Schifferstein 2009; Norton, Mochon, and Ariely 2011). Our study found several examples where aspects of creation have contributed to feelings of psychological ownership. S2 noted how simply changing laces made the shoes more his. All phone owners commented on the value of personalising the phone in a number of ways. C4 had upgraded his vehicle after purchasing it making it uniquely fitting his needs. Two bench users (B1 and B3) were particularly interesting in this regard since they went far out of their way to create a desired experience (meditation, reflecting or otherwise escaping from the city) that was facilitated by the bench and its context. This affordance principle is related to control principles, but differs in a focus on the effort required by the user. An example would be when a user delays gratification for a future reward. In such a case, the user is showing effort (resisting instant gratification) for a reward rather than temporally controlling the use of the object.

Repair and Maintenance of an object requires investment from the user in order to sustain value over time. All four car owners reported repairs and maintenance which seemed to solidify investment in their car. P3 reported breaking a phone and having to replace the screen out of warranty which created closer attention and care. S1 discussed the time and effort that goes into polishing shoes. Many of these activities are what McCracken (McCracken 1986) referred to as grooming rituals - an activity used to keep special possessions in the best condition possible. The investment required to maintain objects increases interaction and a sense of ownership.

Repository refers to the collection of valuables within the target object. As consumers use objects to store valuables, the object itself becomes valuable and a means to 
protecting additional parts of themselves. These stored valuables can be physical (e.g. in a car), or digital (e.g. in a phone). C2 used her car as a repository for her child stroller, baby bag, car seat, and a number of children toys. Great effort had been spent in transforming the car into a place where she felt she could take care of her child. Phone users spend significant effort storing information in the repository of their phone. Collecting contacts, photographs, videos and other information were all tasks that made a phone unique to one user.

Interestingly, this meant that phone users felt ownership over the software contained within the phone and not the hardware. "Look at these two phones" P1 said referring to his iPhone $4 \mathrm{~s}$ and an iPhone $4 \mathrm{~s}$ owned by one of the authors. "They are identical unless you turn them on". It is the content created within the software that distinguished them from each other.

Emblems signal information about the user's identity. The object, brand, and object features can all be emblems. Most participants were conscious of emblems signalling their efforts or stage in life. "An old car with high miles is expected since I am still a student and money is tight" commented C3. P1 and P3 both noted that they enjoyed the phone but also used it to "look the part" in their professional lives. S1 and S2 reflected this same sentiment of needing to fit in with others. In essence, participants used the objects to show who they are or who they are trying to be. They take possession of the object to extend their self-identity (Russell W. Belk 1988).

Preference Recall is the process of remembering settings determined during previous use. People put effort into making an object theirs by configuring it the way they like. When an object is able to recall preferences it allows the user to immediately step back into what they have already created as theirs. P1 reported having significant attachment to the content of the phone but essentially none with the hardware. This is partially because preferences that make the phone theirs are based in software and are easily transferred to new phones. Both 
$\mathrm{C} 1$ and $\mathrm{C} 4$ had cars shared among multiple users. The car would adjust preferences (radio stations, mirror positions, seat position, etc.) depending on which key was used. This allows users to quickly step into the environment they have created. Design can use technology to remember preferences established by users.

\section{Discussion and future research}

This research has presented a framework for object attachment based on psychological ownership. The work presented in this paper contributes to design knowledge by providing a more holistic understanding of object attachment based on the identification of 16 affordance principles. Previous studies have identified various elements of this framework (Jung et al. 2011; Mugge, Schifferstein, and Schoormans 2006) but have fallen short of clearly defining the motives, routes, and affordances to psychological ownership. As shown in Figure 1, these are easily mapped to interaction and experience design models and provide a practical resource for designers.

The affordance categories provide interesting commentary on the user-object interactions found within this study. Control and self-investment affordances generally require active interaction where users are influencing the object. This is in contrast to knowledge affordances that are largely passive and rely on the object influencing the user. Accordingly, the categories of control and self-investment require the active skill of performing a task, and the category of knowledge requires the passive skill of perceiving communicated information. Understanding this distinction aids in considering design decisions. Active interaction requires design features that allow users to influence the object by, for example, changing the object in some way. Passive interaction, however, requires object features that communicate to the user such as a careful selection of materials, geometries, and colours. 
Object attachment should be considered within the context of the entire user experience. Designers and previous users shape the target object and the affordance principles discussed earlier. Designers may directly control object affordances but have much less control over a user's time constraints, cultural meaning, use environment, and mental state. Thus, it may be useful for designers to consider affordance principles within appropriate levels of engagement. There are potentially four levels of engagement: feature, product, context, and experience. An example of feature-level engagement is the repository affordance principle that is based on components of the product. Spatial control is an example of product-level engagement where interest is focused on how a user moves the entire object. Contextual engagement includes principles that reflect culturally or otherwise contextspecific knowledge such as disclosure and emblems. At the experience level, designers need to consider how the larger user experience impacts the relation with the object as seen with the enabling principle. Investigating the levels of engagement associated with the affordance principles may lead to greater insight during the design phase.

This study highlights the need to carefully specify the target of attachment. Phone users reported strong attachment to elements contained in the software rather than the hardware. This is because the software was actually the target (controlled, intimately known, and self-invested). Designs with multiple components, such as hardware and software, benefit from this in that updated hardware is sold periodically but consumers are enticed to stay with the present organisation given the attachment to the software.

Neither the routes nor the affordance principles are mutually exclusive and attachment will likely increase if used together. The objective, however, is not to maximise these but to optimise them. It is easy to see how maximising affordances could lead to a complex and burdensome interaction that may be too daunting for the user to engage with. Optimisation strikes a balance between affordances and constraints to reach the best way to engage users. 
User testing should be conducted throughout the design of any product to validate design decisions.

It is increasingly important to provide individuals with meaningful experiences that fulfil fundamental needs. The first step in fulfilling needs is to understand the process that individuals go through when interacting with or experiencing products. The present study provides the psychological framework to fulfil three needs-efficacy and effectance, selfidentity, and having a place. The examples collected through the 16 object interactions put the framework in context.

\subsection{Limitations and Future Research}

Objects and participants were chosen to get a variety of interactions resulting in many design affordances. A different combination of objects may have highlighted other affordance principles not seen in this study. The number of objects and participants in this study then act as a limitation in the number of identified affordance principles. The current research is not intended to be exhaustive but rather to act as a step towards better understanding how attachment is developed through the motives and routes to psychological ownership.

The bridge from needs to specific behaviours resulting from this research acts as an aid for design researchers and practitioners. Researchers may use this to build on and consolidate previous work on attachment and to inform further understanding of the nuances between actions, affordances, routes, and motives. Practitioners benefit from a framework upon which they can understand and assess consumers' attachment to their offerings. Future work should move beyond the framework to develop a prescriptive design method. One possible approach is to synthesise questions to guide design activity. An example of such a tool is the Design with Intent method (Lockton, Harrison, and Stanton 2010), which helps designers reflect and consider design features at the conceptual stage of design based on 
guiding questions. Another possible prescriptive design method could help designers identify affordance principles with a target group of users or objects and systematically apply the identified affordance principles to other users. This approach would be similar to that of Srivastava and Shu (Srivastava and Shu 2013).

Future research could also apply psychological ownership to various present topics of interest. A desire to own, for example, is one of the greatest hurdles for consumers adopting product-service systems (Tukker 2013). Psychological ownership motives and routes could provide insight to the design of successful product-service systems. Such a study would be especially interesting with regard to time-dependency in developing psychological ownership and if an optimal period of use can be determined.

\section{Conclusion}

The present study has used concepts about psychological ownership and user experience together with observational research to derive a framework to explain how attachment occurs. The framework enables exploration and definition of motives, routes, affordances, and actions related to attachment. It is bidirectional in that attachment motives encourage pursuing actions, and the pursuit of these actions, in turn, fulfils motives leading to attachment. The contextual observations provided rich understanding of each route to attachment and its affordance principles in terms of directionality and scope of interaction. The routes of control and self-investment typically reflect user actions performed upon the object, whereas knowledge is information about the object communicated to the user. Control deals with manipulation of the object spatially or configuration of settings but it refers also to temporal aspects of use including the ability to transform the object over time. Selfinvestment includes the effort that users put into an object as well as the object's ability to recall and safeguard the results of this effort. Intimate knowledge points to the content, 
timing, and medium of the object-owner communication as much as to the resulting experience. Paths to object attachment were found to occur at various levels of engagement: feature, product, context, and experience. Each level has a different set of affordances that are possible. In situations where object attachment is desired, designers can follow the process defined in the framework to understand and develop meaningful paths to attachment via levels of engagement. Engaging users more deeply in one or multiple routes to attachment increases the likelihood of attachment occurring and the intensity of attachment feelings. Thus, attachment to a company brand differs from an offering sold by the company in that users can likely control, know, and invest in the latter at a more intimate level.

\section{Acknowledgements}

Case studies were determined based on familiar objects to the general population and objects often reported as significant to users. There has been no intention of endorsing or otherwise promoting any particular object. We thank the study participants for their time and comments. We also thank the anonymous reviewers for their input and insight that have greatly improved this paper.

\section{References}

Angyal, A. 1941. "Disgust and Related Aversions." The Journal of Abnormal and Social Psychology 36 (3): 393-412. doi:10.1037/h0058254.

Argo, Jennifer J., Darren W. Dahl, and Andrea C. Morales. 2006. "Consumer Contamination: How Consumers React to Products Touched by Others." Journal of Marketing, 8194.

Argo, Jennifer J, Darren W Dahl, and Andrea C Morales. 2008. "Positive Consumer Contagion: Responses to Attractive Others in a Retail Context." Journal of Marketing Research (JMR) 45 (6): 690-701. doi:10.1509/jmkr.45.6.690.

Baer, Markus, and Graham Brown. 2012. "Blind in One Eye: How Psychological Ownership of Ideas Affects the Types of Suggestions People Adopt.” Organizational Behavior and Human Decision Processes 118 (1): 60-71. doi:10.1016/j.obhdp.2012.01.003.

Bardhi, Fleura, and Giana M. Eckhardt. 2012. "Access-Based Consumption: The Case of Car Sharing." Journal of Consumer Research 39 (4): 881-98.

Barnes, Cathy, and Stephen Paul Lillford. 2009. "Decision Support for the Design of Affective Products." Journal of Engineering Design 20 (5): 477-92. doi:10.1080/09544820902875041. 
Baumeister, Christoph, V. Wangenheim, and Florian. 2014. "Access vs. Ownership: Understanding Consumers' Consumption Mode Preference.” SSRN Scholarly Paper ID 2463076. Rochester, NY: Social Science Research Network.

Baxter, Weston L., Marco Aurisicchio, and Peter R. N. Childs. Forthcoming. "Materials, Use and Contaminated Interaction." Materials \& Design.

doi:10.1016/j.matdes.2015.04.019

Belk, Russell W. 1988. "Possessions and the Extended Self." The Journal of Consumer Research 15 (2): 139-68.

Belk, R. W. 1987. "Possessions and Extended Sense of Self." Marketing and Semiotics: New Directions in the Study of Signs for Sale, Mouton de Gruyter, Berlin, Germany, 15164.

Beyer, Hugh, and Karen Holtzblatt. 1997. Contextual Design: Defining Customer-Centered Systems. San Francisco: Morgan Kaufmann. . 1999. "Contextual Design.” Interactions 6 (1): 32-42.

Csikszentmihalyi, Mihaly, and Eugene Halton. 1981. The Meaning of Things: Domestic Symbols and the Self. New York: Cambridge University Press.

Davis, James H., F. David Schoorman, and Lex Donaldson. 1997. “Toward a Stewardship Theory of Management." Academy of Management Review 22 (1): 20-47.

Desmet, Pieter MA, and Paul Hekkert. 2007. "Framework of Product Experience." International Journal of Design 1 (1): 57-66.

Fang, Xiang, Surendra Singh, and Rohini Ahluwalia. 2007. "An Examination of Different Explanations for the Mere Exposure Effect." Journal of Consumer Research 34 (1): 97-103. doi:10.1086/513040.

Ferguson, Scott M., Andrew T. Olewnik, and Phil Cormier. 2014. "A Review of Mass Customization across Marketing, Engineering and Distribution Domains toward Development of a Process Framework." Research in Engineering Design 25 (1): 1130.

Fogliatto, Flavio S., Giovani J. C. da Silveira, and Denis Borenstein. 2012. "The Mass Customization Decade: An Updated Review of the Literature." International Journal of Production Economics 138 (1): 14-25. doi:10.1016/j.ijpe.2012.03.002.

Franke, Nikolaus, Martin Schreier, and Ulrike Kaiser. 2010. "The 'I Designed It Myself' Effect in Mass Customization.” Management Science 56 (1): 125-40.

Gibson, James J. 1977. "The Theory of Affordances.” In Perceiving, Acting, and Knowing, edited by R. E. Shaw and J. Bransford, 67-82. Hillsdale, NJ: Lawrence Erlbaum.

Halme, Minna, Markku Anttonen, Gabriele Hrauda, and Jaap Kortman. 2006. "Sustainability Evaluation of European Household Services." Journal of Cleaner Production, Product Service Systems: reviewing achievements and refining the research agenda, 14 (17): 1529-40. doi:10.1016/j.jclepro.2006.01.021.

Hassenzahl, Marc. 2003. "The Thing and I: Understanding the Relationship between User and Product." In Funology, Human-Computer Interaction Series, edited by Mark A. Blythe, Kees Overbeeke, Andrew F. Monk, and Peter C Wright, Vol. 3, 31-42. Dordrecht: Kluwar Academic. . 2010. "Experience Design: Technology for All the Right Reasons." San Rafael, CA: Morgan \& Claypool.

Hassenzahl, Marc, and Noam Tractinsky. 2006. "User Experience-a Research Agenda." Behaviour \& Information Technology 25 (2): 91-97.

Hejmadi, Ahalya, Paul Rozin, and Michael Siegal. 2004. "Once in Contact, Always in Contact: Contagious Essence and Conceptions of Purification in American and Hindu Indian Children.” Developmental Psychology 40 (4): 467-76. doi:10.1037/00121649.40.4.467. 
Hernandez, M. 2012. "Toward an Understanding of the Psychology of Stewardship." Academy of Management Review 37 (2): 172-93. doi:10.5465/amr.2010.0363.

Holtzblatt, K., J. B. Wendell, and S. Wood. 2004. Rapid Contextual Design: A How-to Guide to Key Techniques for User-Centered Design. San Francisco: Morgan Kaufmann.

ITU. 2014. 'World Telecommunication/ICT Indicators Database.' ITU. Accessed January 20, 2015. http://www.itu.int/en/ITU-D/Statistics/Pages/publications/wtid.aspx.

Isaacs, Susan. 1933. "Social Development in Young Children." British Journal of Educational Psychology 3 (3): 291-94.

Jung, Heekyoung, Shaowen Bardzell, Eli Blevis, James Pierce, and Erik Stolterman. 2011. "How Deep Is Your Love: Deep Narratives of Ensoulment and Heirloom Status." International Journal of Design 5 (1): 59-71.

Kahneman, Daniel. 2011. Thinking, Fast and Slow. New York: Farrar, Straus and Giroux.

Kahneman, Daniel, and Jack L. Knetsch. 1991. "The Endowment Effect, Loss Aversion, and Status Quo Bias.” Journal of Economic Perspectives 5 (1): 193-206.

Kleine, Susan Schultz, and Stacey Menzel Baker. 2004. "An Integrative Review of Material Possession Attachment." Academy of Marketing Science Review 1: 1-29

Krippendorff, Klaus. 2005. The Semantic Turn: A New Foundation for Design. Cambridge, Mass: CRC Press.

Lockton, Dan, David Harrison, and Neville A. Stanton. 2010. "The Design with Intent Method: A Design Tool for Influencing User Behaviour.” Applied Ergonomics 41 (3): 382-92.

Maier, Jonathan R. A., and Georges M. Fadel. 2003. "Affordance-Based Methods for Design,” January, 785-94. doi:10.1115/DETC2003/DTM-48673. . 2009. "Affordance-Based Design Methods for Innovative Design, Redesign and Reverse Engineering." Research in Engineering Design 20 (4): 225-39. doi:10.1007/s00163-009-0064-7.

Martin, Bella, Bruce Hanington, and Bruce M. Hanington. 2012. Universal Methods of Design: 100 Ways to Research Complex Problems, Develop Innovative Ideas, and Design Effective Solutions. Beverly, MA: Rockport Publishers.

McCracken, Grant. 1986. "Culture and Consumption: A Theoretical Account of the Structure and Movement of the Cultural Meaning of Consumer Goods." Journal of Consumer Research 13 (1): 71-84.

Mehta, Raj, and Russell W. Belk. 1991. "Artifacts, Identity, and Transition: Favorite Possessions of Indians and Indian Immigrants to the United States." Journal of Consumer Research, 398-411.

Meigs, Anna S. 1984. Food, Sex, and Pollution: A New Guinea Religion. Rutgers University Press New Brunswick, NJ.

Meskin, Aaron, Mark Phelan, Margaret Moore, and Matthew Kieran. 2013. "Mere Exposure to Bad Art." The British Journal of Aesthetics 53 (2): 139-64. doi:10.1093/aesthj/ays060.

Mugge, Ruth, Hendrik NJ Schifferstein, and Jan PL Schoormans. 2006. “A Longitudinal Study on Product Attachment and Its Determinants." European Advances in Consumer Research 7: 641-47.

Mugge, Ruth, Hendrik N. J. Schifferstein, and Jan P. L. Schoormans. 2010. "Product Attachment and Satisfaction: Understanding Consumers' Post-Purchase Behavior." Journal of Consumer Marketing 27 (3): 271-82. doi:10.1108/07363761011038347.

Mugge, Ruth, Jan P.L. Schoormans, and Hendrik N.J. Schifferstein. 2009. "Emotional Bonding with Personalised Products." Journal of Engineering Design 20 (5): 467-76. doi:10.1080/09544820802698550. 
Nemeroff, Carol, and Paul Rozin. 1994. "The Contagion Concept in Adult Thinking in the United States: Transmission of Germs and of Interpersonal Influence.” Ethos 22 (2): 158-86. doi:10.1525/eth.1994.22.2.02a00020.

Norman, Donald A. 2005. Emotional Design: Why We Love (or Hate) Everyday Things. New York: Basic books.

- 2013. The Design of Everyday Things: Revised and Expanded Edition. New York: Basic Books.

Norton, Michael, Daniel Mochon, and Dan Ariely. 2011. "The'IKEA Effect': When Labor Leads to Love." Harvard Business School Marketing Unit Working Paper, no. 11091.

Oatley, Keith, and Philip N. Johnson-Laird. 1987. "Towards a Cognitive Theory of Emotions." Cognition and Emotion 1 (1): 29-50.

O’Reilly, Lynn, Margaret Rucker, Rhonda Hughes, Marge Gorang, and Susan Hand. 1984. "The Relationship of Psychological and Situational Variables to Usage of a SecondOrder Marketing System.” Journal of the Academy of Marketing Science 12 (3): 5376. doi:10.1007/BF02739319.

Ortíz Nicolás, Juan Carlos, Marco Aurisicchio, and Pieter MA Desmet. 2013. “How Users Experience Great Products.” In . Tokyo.

Peck, Joann, and Suzanne B. Shu. 2009. "The Effect of Mere Touch on Perceived Ownership.” Journal of Consumer Research 36 (3): 434-47. doi:10.1086/597330.

Pierce, Jon L., Tatiana Kostova, and Kurt T. Dirks. 2001. "Toward a Theory of Psychological Ownership in Organizations." Academy of Management Review 26 (2): 298-310. doi:10.5465/AMR.2001.4378028. . 2003. "The State of Psychological Ownership: Integrating and Extending a Century of Research." Review of General Psychology 7 (1): 84.

Porteous, J. Douglas. 1976. "Home: The Territorial Core." Geographical Review, 383-90.

Pucillo, Francesco, and Gaetano Cascini. 2014. "A Framework for User Experience, Needs and Affordances.” Design Studies 35 (2): 160-79. doi:10.1016/j.destud.2013.10.001.

Reb, Jochen, and Terry Connolly. 2007. "Possession, Feelings of Ownership, and the Endowment Effect.” Judgment and Decision Making 2 (2): 107-14.

Reeves, Phil, Chris Tuck, and Richard Hague. 2011. "Additive Manufacturing for Mass Customization.” In Mass Customization, edited by Flavio S. Fogliatto and Giovani J. C. da Silveira, 275-89. Springer Series in Advanced Manufacturing. Springer London.

Richins, Marsha L. 1994a. "Special Possessions and the Expression of Material Values." Journal of Consumer Research 21 (3): 522-33.

. 1994b. "Valuing Things: The Public and Private Meanings of Possessions." Journal of Consumer Research 21 (3): 504-21.

Rozin, Paul, and April E. Fallon. 1987. "A Perspective on Disgust." Psychological Review 94 (1): 23-41. doi:10.1037/0033-295X.94.1.23.

Rozin, Paul, Maureen Markwith, and Clark McCauley. 1994. "Sensitivity to Indirect Contacts with Other Persons: AIDS Aversion as a Composite of Aversion to Strangers, Infection, Moral Taint, and Misfortune." Journal of Abnormal Psychology 103 (3): 495.

Rozin, Paul, Linda Millman, and Carol Nemeroff. 1986. "Operation of the Laws of Sympathetic Magic in Disgust and Other Domains." Journal of Personality 50 (4): 703-12.

Rozin, Paul, Carol Nemeroff, Marcia Wane, and Amy Sherrod. 1989. "Operation of the Sympathetic Magical Law of Contagion in Interpersonal Attitudes among 
Americans." Bulletin of the Psychonomic Society 27 (4): 367-70.

doi:10.3758/BF03334630.

Sartre, Jean-Paul. 2012. Being and Nothingness. New York: Open Road Media.

Schifferstein, Hendrik NJ. 2009. “The Drinking Experience: Cup or Content?” Food Quality and Preference 20 (3): 268-76.

- 2010. "From Salad to Bowl: The Role of Sensory Analysis in Product Experience Research." Food Quality and Preference 21 (8): 1059-67.

Schouten, John W. 1991. "Selves in Transition: Symbolic Consumption in Personal Rites of Passage and Identity Reconstruction." Journal of Consumer Research 17 (4): 412-25.

Shedroff, Nathan. 2001. Experience Design. 1 edition. Indianapolis, Ind: New Riders.

Shu, Suzanne B., and Joann Peck. 2011. "Psychological Ownership and Affective Reaction: Emotional Attachment Process Variables and the Endowment Effect." Journal of Consumer Psychology 21 (4): 439-52.

Snare, Frank. 1972. "The Concept of Property." American Philosophical Quarterly 9 (2): 200-206.

Srivastava, Jayesh, and L. H. Shu. 2012. "Affordances and Environmentally Significant Behavior,” August, 355-63. doi:10.1115/DETC2012-71253.

- 2013. "Affordances and Product Design to Support Environmentally Conscious Behavior.” Journal of Mechanical Design 135 (10): 101006-101006. doi:10.1115/1.4025288.

Stø, Eivind, Harald Throne-Holst, Pla al Strandbakken, and Gunnar Vittersø. 2008. "Review: A Multi-Dimensional Approach to the Study of Consumption in Modern Societies and the Potential for Radical Sustainable Changes." System Innovation for Sustainability: Perspectives, Tukker A, Charter M, Vezzoli C, Stф E, Andersen MM (eds). Greenleaf Publishing: Sheffield, UK, 234-54.

Strahilevitz, Michal Ann, and George Loewenstein. 1998. "The Effect of Ownership History on the Valuation of Objects." Journal of Consumer Research 25 (3).

Tian, Kelly, and Russell W. Belk. 2005. "Extended Self and Possessions in the Workplace." Journal of Consumer Research 32 (2): 297-310. doi:10.1086/jcr.2005.32.issue-2.

Tukker, Arnold. 2013. "Product Services for a Resource-Efficient and Circular Economy-a Review." Journal of Cleaner Production.

Van Hinte, E. 1997. Eternally Yours: Visions on Product Endurance. Rotterdam: 010 Publishers.

Van Nes, Nicole. 2010. "Understanding Replacement Behaviour and Exploring Design Solutions." In Longer Lasting Products: Alternatives to the Throwaway Society, edited by Tim Cooper, 107-32. Surrey: Gower.

Weil, Simone. 1952. The Need for Roots: Prelude of a Declaration of Duties to Mankind. London: Routledge \& Kegan Paul.

Xenakis, Ioannis, and Argyris Arnellos. 2013. "The Relation between Interaction Aesthetics and Affordances." Design Studies 34 (1): 57-73.

You, Hsiao-chen, and Kuohsiang Chen. 2007. "Applications of Affordance and Semantics in Product Design.” Design Studies 28 (1): 23-38. doi:10.1016/j.destud.2006.07.002.

Zajonc, Robert B. 1968. "Attitudinal Effects of Mere Exposure." Journal of Personality and Social Psychology 9 (2p2): 1. 
Table 1. Participant characteristics for car $(\mathrm{C})$, mobile phone $(\mathrm{P})$, shoe $(\mathrm{S})$, and park bench (B) observations

\begin{tabular}{llll}
\hline Name & Gender & Age & Occupation Category \\
\hline C1 & M & $>65$ & Retired \\
C2 & F & $25-35$ & Mother \\
C3 & M & $25-35$ & Graduate Student \\
C4 & M & $45-55$ & Transportation \\
\hline P1 & M & $25-35$ & Technology \\
P2 & M & $<18$ & Student \\
P3 & F & $25-35$ & Business Management \\
P4 & M & $>65$ & Real Estate \\
\hline S1 & M & $25-35$ & Consulting \\
S2 & M & $35-45$ & Healthcare \\
S3 & F & $25-35$ & Business Management \\
S4 & F & $25-35$ & Graduate Student \\
\hline B1 & M & $45-55$ & International Business \\
B2 & Family & $10-55$ & Unknown \\
B3 & F & $25-35$ & Public Relations \\
B4 & Couple & $>65$ & Retired \\
\hline
\end{tabular}


Table 2. Affordance principles for control, intimate knowledge, and self-investment

\begin{tabular}{ll}
\hline Affordance Principle & Description \\
\hline Control & Physically manipulate the object \\
Configuration & Arrange the object settings \\
Temporal & Use of the object when desired \\
Rate & Use as much of the object as desired \\
Transformation & Change the object as a result of interaction \\
Intimate Knowledge & \\
Ageing & Capture stories in object changes as it ages with the user \\
Disclosure & Convey origins and former experiences \\
Periodic signalling & Communicate on an event-dependent basis \\
Enabling & Mediate meaningful experiences \\
Simplification & Eliminate distractions \\
Proximity & Communicate through closeness \\
Self-Investment & Bring something or part of something into existence \\
Creation & Service the object \\
Repair and Maintenance & Collect and store valuables within the object \\
Repository & Signal information about identity \\
Emblems & Preference recall
\end{tabular}




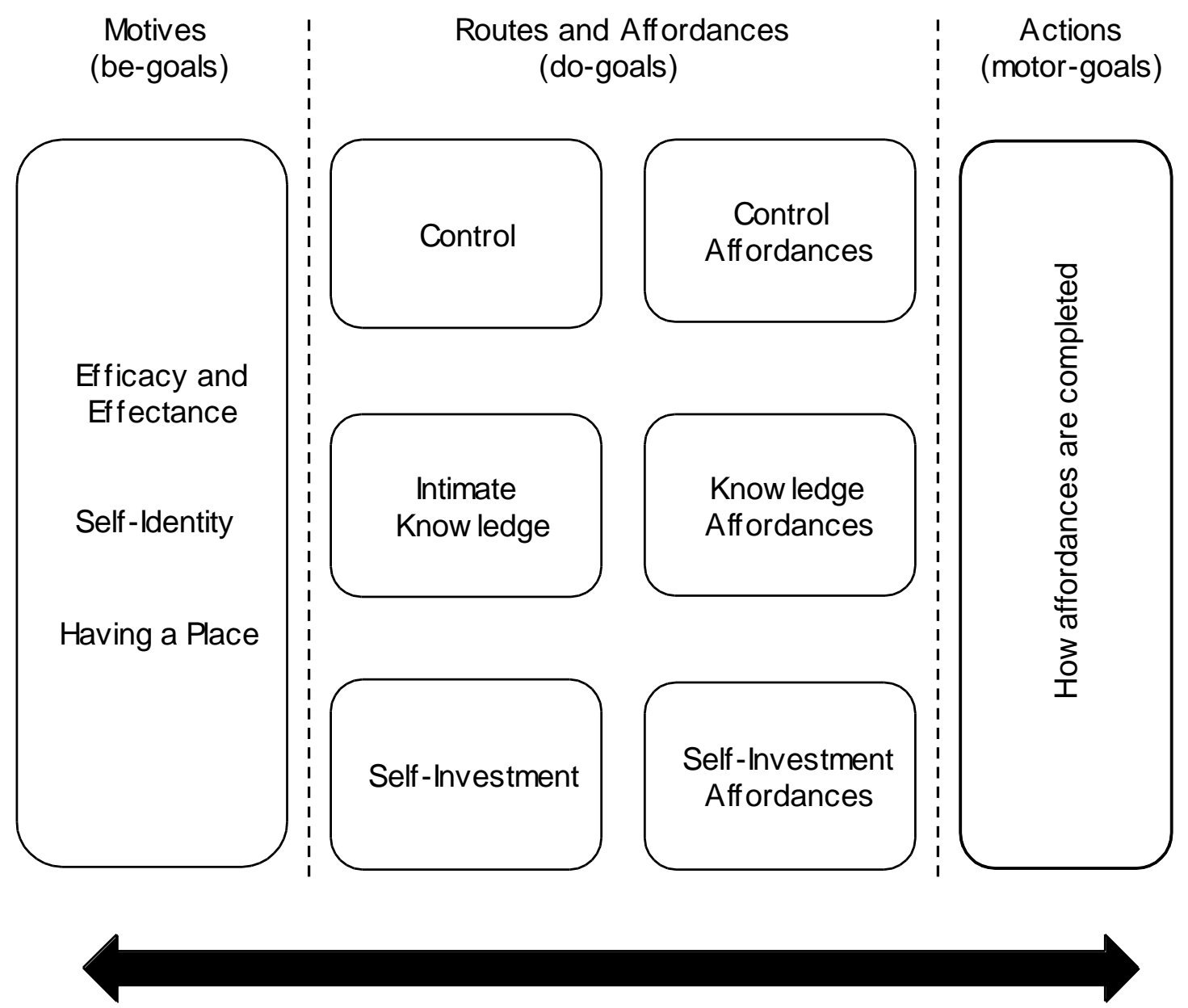

Figure 1. Framework for psychological ownership-based attachment 